\title{
Production, Redistribution, and Inequality
}

\author{
Zakharov A. V., Zakharov V. E. ${ }^{1}$ \\ Received December 1, 2016
}

\begin{abstract}
We use an infinite-dimensional Lotka-Volterra model to analyze production, accumulation, and redistribution of wealth in an economy. We show that, if the amount of wealth produced in the economy is small relative to the amount redistributed, the eventual distribution of wealth will be extremely unequal, with all of it being concentrated in single hands in the limit case. The winner's identity is determined by his ability to redistribute and produce wealth. Similar outcomes are observed in some physical processes. Article is published in the authors' wording.
\end{abstract}

Keywords: redistribution, inequality, Lotka-Volterra model

For citation: Zakharov A. V., Zakharov V.E., "Production, Redistribution, and Inequality", Modeling and Analysis of Information Systems, 24:1 (2017), 5-12.

On the authors:

Alexei Zakharov, National Research University Higher School of Economics,

20 Myasnitskaya str., Moscow 101000, Russia, e-mail: al.v.zakharov@gmail.com

Vladimir Zakharov, doctor of science, University of Arizona, Tucson, USA; Novosibirsk State University, Russia, author ID 7402990981

Acknowledgments:

${ }^{1}$ This work was supported by Russian Science Foundation grant no. 14-22-00174 "Weak turbulence, theory, numerical simulation, experiment".

\section{Introduction}

Worldwide, a substantial fraction of income is redistributed in an unproductive manner a phenomenon often referred to as "rent seeking" by the economic literature. Examples include monopoly rents, profits obtained through regulation and trade restrictions, lobbying, theft (see Mueller, 2003, for a review of literature on the extent of rent seeking), very high executive compensations (Bertrand and Muillanathan, 2001; Bebchuk and Grinstein, 2005), wages in financial sector (Phillipon and Reshev, 2010), corruption (Lambsdorff, 2002), and privatization (Birdsall and Nellis, 2003).

Often, a firm's or an individual's ability to expropriate resources from other economic players is a function of resources that one has already accumulated. More resources means that one becomes more efficient at taking from weaker players (but, possibly, represents a more valuable target for a stronger party). Privatization in post-Soviet Russia is a particular example where rent seeking exhibited such a pattern. Russian privatization resulted in the ownership of the largest industrial enterprises falling to a few individuals. 
Enterprise managers were in a position of an enormous administrative advantage over other participants of the privatization process (particularly, the workers); that advantage was made even stronger by the wealth that they have already accumulated from earlier business deals (Alexeev, 1999).

In this paper we capture such distributional effects of rent-seeking with a dynamic model of wealth production and redistribution. We assume an economy populated by a large number of individuals, each of whom owns a certain amount of wealth. The wealth of each individual changes with time. Each individual has a constant stream of income. The wealth also grows (or declines) at a rate that has two components. First, there is a fixed (and possibly negative) individual-specific rate of return on wealth from productive use. Second, there is a variable component to the rate of return on an individual's wealth that depends on the wealth of other individuals and his rent-seeking abilities vis-a-vis other individuals.

We assume that an individual's rent-seeking ability varies from one person he interacts with to the next. So, individual A may be naturally inclined to expropriate from individual $\mathrm{B}$, but, in turn, be expropriated by individual $\mathrm{C}$. This is a more general assumption than each individual having a scalar proficiency at taking wealth from others. We assume that the individuals are linearly ordered, and each individual is endowed with a fixed, real-valued position. ${ }^{1}$ The relative rent-seeking ability of two individuals is a function of their positions, and the individual-specific component of growth rate also depends on his position. Redistribution is taken to be zero-sum, so no losses are incurred as wealth is shifted between individuals.

Our chief results are that a steady state distribution of wealth is unique and globally stable whenever it exists, and that it becomes unequal if the individual fixed incomes are small. If the functions that govern the rent-seeking and productive activity are taken to be quadratic, then all wealth becomes concentrated in the hands of a single individual as fixed incomes approach zero.

The model used in this work is an infinite-dimensional extension of the well-known Lotka-Volterra dynamic model. In can be used to describe several physical phenomena. Consider, for example, a gas-filled container that is subjected to a powerful flux of electrons. Such a container is likely to become a source of light of a very narrow frequency band - a laser. Generation of light in such medium is described by a mathematical model similar to one used in this work. The state of the system is characterized by the distribution of energy across the frequency spectrum. Energy is transferred between different parts of frequency spectrum (just as wealth is transferred between individuals in this model), while the total amount of energy is constant. As a result, almost all light frequencies are eliminated from the spectrum in a process known as "mode competition" (Haken, 1985).

\footnotetext{
${ }^{1}$ Linear ordering of individuals or firms is a common assumption in economic literature that has been made in several contexts. Individuals may be physically located in different places (Hotelling, 1929), and traveling to a different location entails a cost. Firms may produce differentiated products, with the "distance" between products being their the ease with which they can be substituted for one another (Dixit and Stiglitz, 1977). Finally, different positions may represent different preferences, such as those toward public policy (Downs, 1957; Metlzer and Richards, 1981).
} 


\section{The model}

Consider an economy populated by a continuum of individuals indexed by $k \in[-1,1]$. At every moment of time $t \in[0, \infty)$, individual $k$ possesses wealth $w_{k t}$, with $w_{k 0}>0$. There are three reasons why individual wealth can change with time. First, each individual has a constant stream of income $y_{k}>0$. Second, the stock of wealth grows (or depreciates) at a fixed rate $\gamma_{k}$. Finally, the wealth is redistributed between individuals. We assume that the rate at which wealth is transferred between individuals $k$ and $k^{\prime}$ is proportional to the wealth of each individual and to constant $T_{k k^{\prime}}$. We assume that the interactions between individuals are purely redistributive, so

$$
T_{k k^{\prime}}=-T_{k^{\prime} k}
$$

If $T_{k k^{\prime}}>0$, then individual $k^{\prime}$ is a donor with respect to the recepient individual $k$; the situation is reversed if $T_{k k^{\prime}}<0$, and no transfer of wealth between the individuals takes place if $T_{k k^{\prime}}=0$. Condition (1) demands that $T_{k k}=0$. Assume that $T_{k k^{\prime}}$ is a twice differentiable function on $[-1,1]^{2}$.

It follows that the wealth of individual $k$ changes according to the following rule:

$$
\frac{\partial w_{k t}}{\partial t}=w_{k t} \Gamma_{k t}+y_{k}, \text { where } \Gamma_{k t}=\gamma_{k}+\int_{-1}^{1} T_{k k^{\prime}} w_{k^{\prime} t} d k^{\prime}
$$

Note that the wealth of individuals never turns negative, as differential equations (2) have a solution

$$
w_{k t}=w_{k 0}+y_{k} e^{-\Gamma_{k t}} \int_{0}^{t} e^{-\Gamma_{k \tau}} d \tau .
$$

A steady-state solution to equations (2) are wealth levels $\bar{w}_{k}$ such that the wealth is constant for each individual, or

$$
\bar{w}_{k}\left(\gamma_{k}+\int_{-1}^{1} T_{k k^{\prime}} \bar{w}_{k^{\prime}} d k^{\prime}\right)+y_{k}=0 .
$$

We are going to study the properties of the steady state. A necessary condition for the existence of a steady state is that the function $\gamma_{k}$ should be negative for some values of $k$. Indeed, because of (1), it is true that

$$
\frac{\partial}{\partial t} \int_{-1}^{1} w_{k t} d k=\int_{-1}^{1} \gamma_{k} w_{k t} d k+\int_{-1}^{1} y_{k} d k
$$

Since the last integral is positive, a steady state $w_{k t}=\bar{w}_{k}$ is possible only if

$$
\int_{-1}^{1} \gamma_{k} \bar{w}_{k} d k<0
$$

So, steady-state wealth levels exist only if at least one individual has a negative rate of return from productive activity; otherwise, the wealth of some individuals will grow without bound.

We now show that the steady state, whenever it exists, is unique. 
Theorem 1. There exists at most one $\bar{w}_{k}$ satisfying (4). Whenever it exists, it is globally stable, so for any $w_{k 0}$ we have

$$
\lim _{t \rightarrow \infty} w_{k t}=\bar{w}_{k}
$$

for all $k \in[-1,1]$.

This is a variant of the well-known $H$-theorem for dynamic systems. We show that a measure of enthropy of the system is always increasing, reaching a unique global maximum at the steady state. ${ }^{2}$

Our next goal is to analyze the steady state of the system if the fixed incomes $y_{k}$ are small for all $k$. We do it for a special case of the model.

Theorem 2. Let $y_{k}=y$ and suppose that $\gamma_{k}$ and $T_{k k^{\prime}}$ are second-degree polynomials:

$$
\gamma_{k}=k+c k^{2} \quad \text { and } \quad T_{k k^{\prime}}=k^{\prime}+k^{\prime 2}-k-k^{2} .
$$

Denote by $\Omega$ the set of all $k$ such that

$$
\lim _{y \rightarrow 0} \bar{w}_{k} \neq 0 .
$$

Then $\Omega=\{0\}$.

We show that, as the fixed incomes decline, the steady-state wealth is increasingly concentrated in the hands of a single individual. In the limit case, all individuals except $k=0$ have zero wealth. Figure 1 shows the steady state distribution of wealth for different values of $y$.

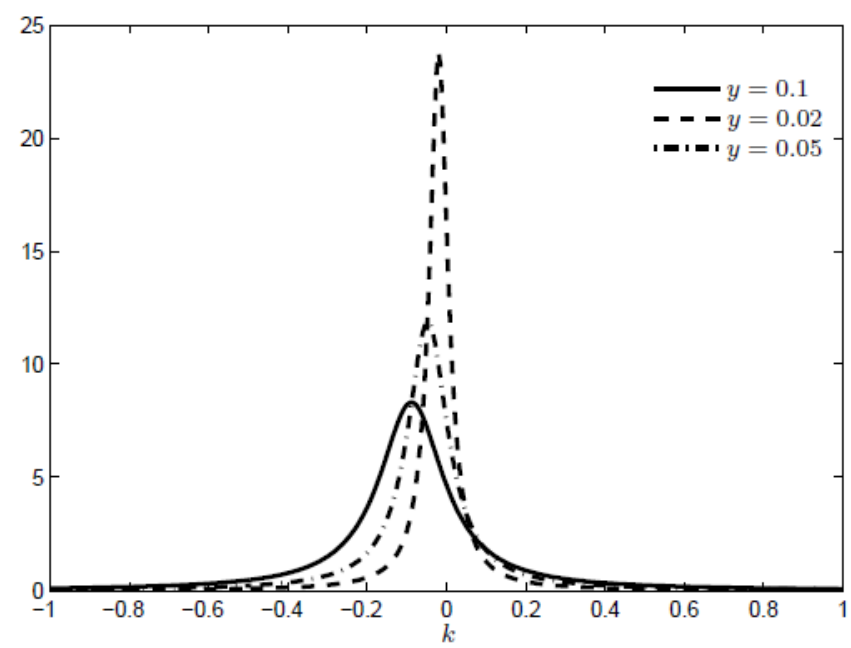

Fig 1: Steady state $\bar{w}$

The identity of the individual who eventually accumulates all wealth in the economy is determined by the capacity of individuals for both rent-seeking and productive economic

\footnotetext{
${ }^{2}$ Formal proofs of the statements are in the Appendix.
} 
activity. Individual $k_{1}=-\frac{1}{4}$ is the only one with $T_{k k^{\prime}} \geq 0$ for all $k^{\prime} \in[-1,1]$, so he enjoys a rent-seeking advantage against almost everyone else; however, his return on wealth $\gamma_{k_{1}}$ is too small, so his wealth depreciates faster than he can expropriate others. Individual $k_{2}=1$ has the highest rate of return $\gamma_{k_{2}}=1+c$, but is incapable of protecting his wealth from others. Both of them, as well as everyone else, eventually lose their wealth to individual $k=0$.

\section{Discussion}

In this work we analyze a steady-state distribution of wealth in a rent-seeking economy in which wealth is constantly being redistributed between individuals. Each individual is assumed to have a one-dimensional spatial position. It is assumed that the magnitude and direction of redistribution between any two individuals is determined by their wealth and their spatial positions, while the redistribution itself is zero-sum. Depending on the positions of individuals $\mathrm{A}$ and $\mathrm{B}$, either one of them is a donor and another - a recipient, or there is no transfer of wealth between the two.

We show that in such an economy there exists at most one steady state, which is globally stable. If the functions $T$ and $\gamma$ governing rent seeking and productive activity are quadratic, the steady-state distribution of income becomes extremely unequal as fixed incomes become small; ultimately, all wealth is accumulated by a single individual. Similar results - that inequality is sometimes a natural outcome of simple economic dynamics - have been shown in computer simulations (Epstein and Axtell, 1996).

Our results can be extended in several ways. First, we expect the latter result to hold for almost all twice continuously differentiable redistirbution and growth functions. Continuity of the rent-seeking function implies that an individual who is a donor (or a receipent) to someone else is also a donor (recepient) to his close neighbors. Whenever there exists a steady-state solution for fixed incomes approaching zero, all wealth in the limiting case will be concentrated by a finite number of individuals out of a continuum. We believe that this result will fail to hold only for a non-generic subset of rent-seeking and growth functions. ${ }^{3}$ Thus we predict that, whenever the magnitude of rent-seeking exceeds that of productive activities, we should expect to observe high inequality.

Second, we think that the limit steady-state solution for fixed incomes approaching zero should be invariant with respect to the exact sequence of fixed incomes. So, the limit steady-state solution is determined uniquely by the rent-seeking and growth functions $T$ and $\gamma$. Finally, we expect the limit steady state to exist for a generic subset of functions $T$ and $\gamma$.

\section{Appendix}

\section{Proof of Theorem 1.}

Denote

$$
H_{t}=\int_{-1}^{1}\left(\bar{w}_{k t} \ln w_{k t}-w_{k t}+\bar{w}_{k}-\bar{w}_{k} \ln \bar{w}_{k}\right) d k
$$

\footnotetext{
${ }^{3}$ For example, using the "finite shyness" notion of non-genericity (Anderson and Zame, 2001).
} 
Introducing $X_{k t}=\frac{w_{k t}}{\bar{w}_{k}}>0$, we can rewrite $H_{t}$ as

$$
H_{t}=\int_{-1}^{1} \bar{w}_{k}\left(\ln X_{k t}+1-X_{k t}\right) d k
$$

The function $f\left(X_{k t}\right)=\ln X_{k t}+1-X_{k t}$ is negative for all $X_{k t}$, except for $f(1)=0$. It follows that $H_{t} \leq 0$, with $H_{t}=0$ if and only if $w_{k t}=\bar{w}_{k}$ for all $k=1, \ldots, N$.

From (4) we have

$$
\gamma_{k}=-\int_{-1}^{1} T_{k k^{\prime}} \bar{w}_{k^{\prime}} d k^{\prime}-\frac{y_{k}}{\bar{w}_{k}}
$$

Substituting this into (2), we obtain

$$
\frac{\partial w_{k t}}{\partial t}=w_{k t} \int_{-1}^{1} T_{k k^{\prime}}\left(w_{k^{\prime} t}-\bar{w}_{k^{\prime}}\right) d k^{\prime}+y_{k}\left(1-\frac{w_{k t}}{\bar{w}_{k}}\right) .
$$

Now we can calculate

$$
\frac{\partial H_{t}}{\partial t}=-\int_{-1}^{1} \int_{-1}^{1} T_{k k^{\prime}}\left(w_{k t}-\bar{w}_{k}\right)\left(w_{k^{\prime} t}-\bar{w}_{k^{\prime}}\right) d k d k^{\prime}+\int_{-1}^{1} y_{k} \frac{\left(w_{k t}-\bar{w}_{k}\right)^{2}}{w_{k t} \bar{w}_{k}} d k .
$$

As we assume $T_{k k^{\prime}}=-T_{k^{\prime} k}$, the first sum on the right-hand side of this equation is equal to zero. That gives us

$$
\frac{\partial H_{t}}{\partial t}=\int_{-1}^{1} y_{k} \frac{\left(w_{k t}-\bar{w}_{k}\right)^{2}}{w_{k t} \bar{w}_{k}} d k>0
$$

so $\frac{\partial H_{t}}{\partial t}$ increases whenever the economy is not in a steady state. It follows that a steady state is a global attractor.

We now show that the steady state is unique. Suppose $\bar{w}$ and $\bar{w}^{\prime}$ are two different steady states, and let $A$ be the set of all $k$ such that $\bar{w}_{k} \neq \bar{w}_{k}^{\prime}$. Then $A$ must have measure 0 , with $\bar{w}_{k}$ and $\bar{w}_{k}^{\prime}$ finite for all $k \in A$. Otherwise, by (13) we will have $\frac{\partial H_{t}}{\partial t}>0$, contradicting the assumption that either $\bar{w}$ or $\bar{w}^{\prime}$ is a steady state. As $A$ has measure 0 and $\bar{w}_{k}$ and $w_{k}^{\prime}$ are finite for all $k \in A$, for all $k$ we should have

$$
\int_{-1}^{1} T_{k k^{\prime}} \bar{w}_{k^{\prime}} d k^{\prime}=\int_{-1}^{1} T_{k k^{\prime}} \bar{w}_{k^{\prime}}^{\prime} d k^{\prime}
$$

where by (4) we have $\bar{w}_{k}=\bar{w}_{k}^{\prime}$. Q.E.D.

\section{Proof of Theorem 2.}

If $\gamma_{k}, T_{k k^{\prime}}$ are given by (8), the steady-state solution must satisfy

$$
\bar{w}_{k}\left(\gamma_{k}+\int_{-1}^{1} T_{k k^{\prime}} \bar{w}_{k^{\prime}} d k^{\prime}\right)=-y
$$

or

$$
\bar{w}_{k}=\frac{y}{\left(N_{0}-c\right) k^{2}+\left(N_{0}-1\right) k-N_{1}-N_{2}}=\frac{y}{\Delta(k)},
$$

where

$$
N_{0}=\int_{-1}^{1} \bar{w}_{k} d k, \quad N_{1}=\int_{-1}^{1} k \bar{w}_{k} d k, \quad \text { and } \quad N_{2}=\int_{-1}^{1} k^{2} \bar{w}_{k} d k
$$


As $\Delta(k)$ must be positive for all $k \in[-1,1]$, it must be that $N+0-c>0$. We can thus rewrite

$$
\Delta(k)=\left(N_{0}-c\right)\left[(k+a)^{2}+b^{2}\right]
$$

where

$$
2 a\left(N_{0}-c\right)=N_{0}-1 \quad \text { or } \quad a=\frac{N_{0}-1}{2\left(N_{0}-c\right)},
$$

and

$$
\left(b^{2}+a^{2}\right)\left(N_{0}-c\right)=-N_{1}-N_{2}
$$

The last equation implies that $N_{1}+N_{2}<0$ or, as $N_{2}$ is positive, that $N_{1}<0$, so the density of $\bar{w}_{k}$ is maximal for some $k<0$. Now we have

$$
N_{0}=\frac{y}{N_{0}-c} \int_{-1}^{1} \frac{d k}{(k+a)^{2}+b^{2}}=\frac{y}{b\left(N_{0}-c\right)}\left(\arctan \frac{1+a}{b}+\arctan \frac{1-a}{b}\right) .
$$

We can similarly express $N_{1}$ and $N_{2}$ in terms of $a$ and $b$; however, we will not be able to obtain a closed-form solution for $a$ and $b$ in terms of model fundamentals $c$ and $y$. It might be possible only in the limiting case $y \rightarrow 0$. As the arctangent function is finite, it follows from (15) that $b \rightarrow 0$ as $y \rightarrow 0$. Assuming $a<1$, we have

$$
b \simeq \frac{\pi y}{N_{0}\left(N_{0}-c\right)}
$$

for small values of $y$. After some rearrangement we obtain

$$
-c\left(a^{2}+b^{2}\right)+\frac{2 y}{N_{0}-c}-a(1-2 a) N_{0}+\frac{y(1-2 a)}{N_{0}-c} \int_{-1}^{1} \frac{k+a}{(k+a)^{2}+b^{2}} d k=0 .
$$

Notice that

$$
\int_{-1}^{1} \frac{k+a}{(k+a)^{2}+b^{2}} d k=\frac{1}{2} \ln \frac{(1+a)^{2}+b^{2}}{(1-a)^{2}+b^{2}} .
$$

For $a$ and $b$ close to zero, we have

$$
\int_{-1}^{1} \frac{k+a}{(k+a)^{2}+b^{2}} d k \simeq 2 a
$$

Here the integral term is second order in $y$. Collecting together first-order terms of $y$ one gets

$$
a \simeq \frac{2 y}{N_{0}\left(N_{0}-c\right)}
$$

The statement of the theorem follows, as

$$
\lim _{y \rightarrow 0} \bar{w}_{k}=0
$$

for any $k \neq 0$. 


\section{References}

[1] Alexeev Michael, "The effect of privatization on wealth distribution in Russia", Economics of Transition, 7(2) (1999), 449-465.

[2] Anderson Robert M., William R. Zame, "Genericity with Infinitely Many Parameters", Advances in Theoretical Economics, 1(1) (2001), DOI: 10.2202/1534-5963.1003.

[3] Bebchuk Lucian, Yaniv Grinstein, "The Growth of Executive Pay", Oxford Review of Economic Policy, 21(1), 2005, 283-303.

[4] Bertrand Marianne, Sendhil Mullainathan, "Are CEOS Rewarded for Luck? The Ones without Principals Are", The Quarterly Journal of Economics, 116(3) (2001), 901-932.

[5] Birdsall Nancy, John Nellis, "Winners and Losers: Assessing the Distributional Impact of Privatization", World Development, 31(10) (2003), 1617-1633.

[6] Dixit Avinash K., Joseph E. Stiglitz, "Monopolistic Competition and Optimum Product Diversity", The American Economic Review, 67(3) (1977), 297-308.

[7] Downs Anthony, "An Economic Theory of Political Action in a Democracy", The Journal of Political Economy, 1957, 135-150.

[8] Epstein Joshua M., Robert Axtell, Growing Artificial Societies: Social Science from the Bottom Up, Brookings Institution Press, 1996.

[9] Haken H., Light. V. 2: Laser Light Dynamics, Horth-Holland, 1985.

[10] Hotelling Harold, "Stability in Competition", The Economic Journal, 39(153) (1929), $41-57$.

[11] Lambsdorff Johann G., "Corruption and Rent-seeking", Public Choice, 113, 2002, 97-125.

[12] Meltzer Allan H., Scott F. Richard, "A Rational Theory of the Size of Government", The Journal of Political Economy, 1981, 914-927.

[13] Mueller Thomas, Public Choice III, Cambridge University Press, 2003.

[14] Philippon Thomas, Ariell Reshef, Wages and Human Capital in the US Financial Industry: 1909-2006, No. w14644, National Bureau of Economic Research, 2009.

Захаров А. В., Захаров В. Е., "Перераспределение, производство и неравенство", Моделирование и анализ информачионных систем, 24:1 (2017), 5-12.

DOI: $10.18255 / 1818-1015-2017-1-5-12$

Аннотация. Мы используем бесконечномерную модель Лотки-Вольтерра для анализа производства, накопления и перераспределения богатства в экономике. Мы показываем, что если объем производства по сравнению с объемом перераспределения невелик, то итоговое распределение богатства будет очень неравным. В предельном случае, все богатство будет сконцентрировано в одних руках. Личность победителя определяется его способностью производить и перераспределять богатство. Похожие исходы можно наблюдать и для некоторых физических процессов. Статья публикуется в авторской редакции.

Ключевые слова: перераспределение, неравенство, модель Лотка-Вольтерра

Об авторах:

Захаров Алексей Владимирович, Национальный Исследовательский Университет "Высшая Школа Экономики", ул. Мясницкая, 20, Москва, 101000 Россия, e-mail: al.v.zakharov@gmail.com

Захаров Владимир Евгеньевич, доктор физико-математических наук, академик РАН,

Новосибирский государственный университет, Россия

Аризонский университет, США, ID 7402990981

Благодарности:

Работа выполнена при финансовой поддержке Российского научного фонда, проект №14-22-00174. 